\title{
Meta-analysis of methane yields from anaerobic digestion of dairy cattle manure.
}

Nicole D. Miranda ${ }^{\mathrm{a}, *}$, Ramon Granell ${ }^{\mathrm{b}}$, Hanna L. Tuomisto ${ }^{\mathrm{c}}$, Malcolm D. McCulloch ${ }^{\mathrm{a}}$.

${ }^{a}$ Energy and Power Group, Department of Engineering Science, University of Oxford, Oxford, UK.

E-mails: [nicole.miranda; malcolm.mcculloch]@eng.ox.ac.uk

${ }^{b}$ Oxford e-Research Centre, University of Oxford, Oxford, OX1 3QG, UK.

${ }^{c}$ European Commission, Joint Research Centre (JCR), Institute for Environment and Sustainability, Via Enrico Fermi 2749, 21027 Ispra, Italy.

\begin{abstract}
This work presents a novel meta-analysis for methane yields from anaerobically digesting dairy cattle manure. A database is compiled from 115 articles (2,181 cases) by systematically assessing the academic literature. $Y_{\mathrm{CH} 4}$ and secondary variables collected in the database describe performance, operation conditions of digester and manure composition. Inputs to the database are normalised to enable inter-study uni- and multi-variate analysis, according to different types of digesters.

Most cases $(\mathrm{N}=1,299)$ are reported for batch digesters and meta-analysis results in a mean $Y_{C H 4}$ of $0.230 \pm 0.016 \mathrm{~m}^{3} \mathrm{~kg}^{-1}$. CSTR $(\mathrm{N}=241)$, results in mean of $0.190 \pm 0.016$ $\mathrm{m}^{3} \mathrm{~kg}^{-1}$ (random-effect model). Other continuous digesters, such as fixed-film, plug-flow and UASB require further cases for the application of meta-analysis. For non-specified semi-continuous digesters $(\mathrm{N}=347)$, the mean calculated by the random-effect model is $0.204 \pm 0.032 \mathrm{~m}^{3} \mathrm{~kg}^{-1}(\mathrm{~N}=27)$.

With respect to multi-variate analysis of operation conditions, batch digesters form four clusters, while two clusters are identified for CSTR and three for semi-continuous digesters. For variables describing manure composition, batch digesters present eight clusters, while CSTR and semi-continuous digesters have insufficient cases. The strongest correlations found for these secondary variables (Spearman's rho: -0.685 and -0.696 ) result for $\mathrm{pH}$ and $\mathrm{Y}_{\mathrm{CH} 4}$ in batch and CSTR, respectively.

Maximum $Y_{\mathrm{CH} 4}$ estimated by meta-analysis are proposed to replace the default IPCC values because they are based on a larger sample size and integrate updated literature. In particular, markedly higher $Y_{C H 4}$ are obtained for Asia, Middle East and Indian Subcontinent than those in the IPCC guidelines.
\end{abstract}

Keywords: Anaerobic digestion, biogas, methane yield, dairy, manure management.

*Corresponding author. Email: nicole.miranda@eng.ox.ac.uk 


\section{Introduction}

This meta-analysis examines the methane yields $\left(Y_{\mathrm{CH} 4}\right)$ found in the literature for anaerobic digestion (AD) of dairy cattle manure. The dairy sector is responsible for $4 \%$ of global anthropogenic greenhouse gas (GHG) emissions [1]. To reduce the carbon footprint of milk-producing farms, AD has been proposed as a mitigating technology. $\mathrm{AD}$ converts the volatile solids (VS) in cattle manure to biogas $\left(\mathrm{CH}_{4}\right.$ and $\mathrm{CO}_{2}$ mixture) and digestate [2]. Consequently, GHG emissions are decreased by: i) avoiding high global warming $\mathrm{CH}_{4}$ from manure management systems; ii) generating renewable energy that substitutes fossil fuels and; iii) producing digestate that replaces mineral fertilisers. In order to quantitatively predict these benefits, assumptions on the performance of AD processes are critical [3].

In this respect, $\mathrm{Y}_{\mathrm{CH} 4}$ is a metric widely utilised in mass and energy balances to calculate the $\mathrm{CH}_{4}$ production. The $Y_{\mathrm{CH}}$ corresponds to the $\mathrm{CH}_{4}$ formed by unit of VS and is defined as follows:

$$
Y_{C H 4}\left[m^{3} \mathrm{~kg}^{-1}\right]=\frac{C H_{4, \text { output }}}{V S_{\text {input }}}
$$

Theoretical, modelled and experimental values of $Y_{C H 4}$ are available in the literature. Theoretical estimates commonly use the Buswell equation $[4,5]$ which is based on the chemical composition and stoichiometry of degradation reactions. However, actual $Y_{C H 4}$ are less than theoretical values because not all organic material converts to biogas (e.g. non-degradable solids, inhibition of reaction and/or generation of new bacteria). Thus, utilising theoretical $\mathrm{Y}_{\mathrm{CH} 4}$ can over-estimate $\mathrm{CH}_{4}$ production for $\mathrm{AD}$ scenarios. For models of $Y_{C H 4}$ (e.g. ADM1 [6] and Linke et al. [7]), validations are based on experimental work with limited AD operation conditions. Therefore, increasing the sample size of experimental results can provide a more robust source of validation. 
Although, empirical values of $Y_{C H 4}$ are available in multiple (and increasing) publications, it is challenging to integrate results differing in operation conditions, slurry compositions and units of measurements. This work addresses this by applying meta-analysis techniques to systematically review and numerically combine the research on $Y_{C H 4}$ in the dairy sector.

Meta-analysis has traditionally developed in the medical sciences but in recent years has been applied in the the bio-energy sector $[8,9]$. For biogas generation from dairy farms, qualitative reviews are dominant [10-12]. Only two meta-analysis [13, 14] exist for $\mathrm{AD}$ of dairy manure, however, they are focused on different aspects of the process (i.e. microbial communities [13] and the effects over farm emissions [14]). Additionally, to the authors' knowledge, this is the first work to integrate such numerous cases from the academic literature in the field.

The aim of this meta-analysis is to quantitatively combine $Y_{C H 4}$ measurements to enable a comprehensive understanding of this metric with respect to operational and composition variables. For this purpose, two main steps are carried out: creating a specific database and statistically analysing the collected information. A database is compiled because no specific dataset is available for the entire literature reporting $Y_{C H 4}$ of $\mathrm{AD}$ in dairy farms. Research articles are found by using particular keywords and applying defined criteria (Section 2.1). The $Y_{C H 4}$ are extracted from the selected work and entered to the database together with secondary variables (i.e. specifying operation and/or manure composition). In order to enable numerical combination, units of measurements for all variables are standardised (Section 2.2). To analyse the variables compiled in the database, uni- and multi-variate tests are introduced in Sections 2.3-2.4. In the Results and Discussion section, key aspects of the database are first described (Section 3.1). Thereafter, $Y_{C H 4}$ are discussed in terms of digester type (i.e. batch, continuous or semi-continuous). Multi-variate structure between key variables related to 
the performance of different AD systems is examined. Correlations and clustering of principal components are discussed in terms of sources of similarities and variations. The discussion finally compares results of meta-analysis models applied over maximum $Y_{C H 4}$ to the default values of the National Guidelines for GHG emissions of the Intergovernmental Panel of Climate Change (IPCC [15], i.e. widely used to predict $\mathrm{CH}_{4}$ emission from manure management systems).

\section{Methods}

This section first presents the methodology to develop the novel database of $Y_{\mathrm{CH} 4}$ for AD of dairy cattle manure. Second, the mathematical background for the statistical analysis of the variables in the database is introduced. All statistical calculations are performed in R v.3.0.2.

\subsection{Article selection}

A systematic search of articles in the academic literature is carried out to compile the database of $Y_{\mathrm{CH} 4}$ of dairy cattle manure and secondary variables. The selection of articles is based on the following four criteria:

i) scientific publications in the academic literature that have been peer-reviewed and are in the field of $\mathrm{AD}$;

ii) primary sources;

iii) available work in journals in English to which the authors have access and;

iv) inclusion of experimental data of $Y_{C H 4}$ for AD of dairy cattle manure.

The first criterion is defined to ensure quality results in articles that potentially report $Y_{C H 4}$ values. The ISI Web of Knowledge platform [16] is used because it contains mainly peer-reviewed journals. The publication language is set as "English" and the publication year is not constrained. It should be noted that, although China has played an important role in the development of AD plants (e.g. by 2007 it had 26.5 million 
biogas plants installed [17]), articles written in Chinese are discarded by this criterion. Similarly occurs for publications from India [18]. This is significant constraint of the language criterion. However, as results will show, the selection of English articles in this work markedly contributes in bringing together a large sample size.

Keywords, logical connectors and combinations shown in Figure 1 are used for the search of articles. The keywords aim to identify technology presence, agricultural sector and the metric of interest for this meta-analysis.

-Figure 1 here-

From the search results, titles and abstracts are used for a first filtering step. They are assessed to determine if studies report mono-digestion of dairy cattle manure and are primary sources (i.e. the latter corresponds to the fulfilment of the second criteria). Secondary sources are excluded to avoid duplicated values in the database. Therefore, review articles are rejected in this step. In addition, articles from a same author are verified to not repeat cases in the database.

From the titles and abstracts, articles available to the authors are collected (i.e. third criteria). The final filter step consists of selecting papers that include quantitative and empirical results (in text, tables or figures) of $Y_{\mathrm{CH}}$ for dairy cattle manure, thus, complying with the fourth criteria.

\subsection{Database input}

$Y_{C H 4}$ are extracted from the selected articles to compile the database. Values of of $Y_{C H 4}$ are adapted so that all cases correspond to cumulative $\mathrm{CH}_{4}$ production per kilogram of VS. $Y_{C H 4}$ values are standardised to normal conditions $\left(20{ }^{\circ} \mathrm{C}, 1 \mathrm{~atm}\right)$ and given in " $\mathrm{m}^{3} \mathrm{~kg}^{-1}$ " (i.e. volume of methane produced per mass of VS fed to digester.

When articles report various $Y_{C H 4}$ (e.g. profiles across time or measurements at different temperatures), multiple cases are logged into the database. To record differences between cases, secondary variables are also entered to the database (when available). 
Qualitative secondary variables are: author name, journal name, year of publication and location of study (country and/or continent). If the latter is not available, the location of the first author is used. For quantitative secondary variables, the first column of Table 1 shows those that are found most frequently in the literature for AD of dairy cattle manure, thus, used in this work. These variables specify AD operation conditions and chemical compositions of the undigested slurries (i.e. before entering the digester). The units of measurements for secondary quantitative variables are also presented in Table 1. If a variable is reported in different dimensions, underlying data from the original article is utilised to reconcile the units. If insufficient information is available when dimension conversion is required, the original units of measurements are recorded into the database, but the variable is excluded for numerical analysis. -Table 1 here-

To ensure that comparable experiments are combined, the results are presented separately according to type of digester (batch, continuous and semi-continuous) and differences are discussed.

\subsection{Uni-variate analysis}

Having the variables standardised to the required unit of measurement, normality of the distributions is assessed by the Shapiro-Wilk test [19]. Inter-quartile ranges (IQRs) are reported to examine the dispersion of the variables of the database. Because of the expected non-normal distributions of $Y_{C H 4}$, Wilcoxon Signed Rank test [20] is used to evaluate significant differences between distributions.

-Table 2 here-

In order to obtain novel effect sizes (i.e. $Y_{C H 4}$ ) that synthesise the literature, meta-analysis models were applied to the distributions from the database. Fixed- and random-effect models are applied given the mean $\left(M_{i}\right)$, standard deviation $\left(s_{i}\right)$ and sample size $\left(N_{i}\right)$ for each case "i". The calculations undertaken to evaluate the new $Y_{C H 4}$ 
from this work, are summarised in Table 2. The main difference between the models is that the fixed-effect model considers that each case corresponds to a measurement of effect size from a population with unique mean $(\boldsymbol{\mu})$. The estimation of $\mu$ is reported as $M$. For this model, the variance $\left(V_{i}\right)$ is calculated with respect to $\mu$. The random-effect model, in contrast, assumes a distribution of the population, hence multiple $\mu_{i}$. To account for this, the model measures the variability of $M_{i}$ with respect $\mu_{i}$ and of $\mu_{i}$ with respect to $\mu$.

\subsection{Multi-variate analysis}

To assess the overall effect of the secondary variables in Table 1 over the $Y_{C H 4}$, correlations are examined by using the Spearman Rank test [21]. This test determines $(\mathrm{p}<0.05)$ if the relation between variables is monotonic (non-specific to linear relations). This test is chosen because it is a robust method in the presence of outliers.

Principal component analysis is combined with cluster-analysis to study the underlying structure of the operation conditions and slurry compositions. This approach is adopted from Brambilla et al. [22]. As a first step, the most reported variables describing AD systems in the literature are identified to undergo principal component analysis. This technique is a unsupervised pattern-recognition method that allows reduction of dimensionality for multivariate datasets [23]. The dimension reduction allows visualisation of the database and synthesis of the data collected from the numerous cases in the database. Results of first and second principal components are presented by score plots.

As a second step, different groups of cases in the database are analysed by applying the most used clustering algorithm (k-means [24]) over the first two principal components. K-means clustering depends on the initialisation, therefore, experiments are repeated over 100 initial random centroids for 2 to 10 clusters. The number of clusters is defined 
by selecting the best Davies-Bouldin Index (DB Index) score from the k-means output [24].

\section{Results and discussion}

This section presents the outcomes of the database development and statistical analyses in five subsections. The first subsection covers results from the application of filtering criteria, general overview of the typology of the papers that conform the database (e.g. year of publication and journal) and introduction to types of digester found in the literature. The second to fourth subsections report the $Y_{C H 4}$ for batch, continuous and semi-continuous AD-systems, respectively. $Y_{C H 4}$ and its relation to secondary variables are examined by uni- and multi-variate analysis for these different types of digesters. In the last subsection, the meta-analysis of maximum $\mathrm{CH}_{4}$ potentials is discussed to improve those currently used by IPCC.

\subsection{Database development}

The search of papers using the word combination described in the methods section, outputs 888 publications. By assessing these papers against the selection criteria (i.e. peer-reviewed research articles in the field of interest), 115 articles (fraction equivalent to $13.0 \%$ of the initially found) are chosen to construct the database (publicly available on the website of the Energy and Power Group from the University of Oxford: epg.eng.ox.ac.uk/content/anaerobic-digestion). The causes for the high rejection, according to criteria, are shown in Figure 2a.

-Figure 2 here-

Within the papers rejected by the first criterion, 352 correspond to other feedstock; 43 co-digest dairy cattle manure with other organic waste, excluding specific $Y_{\mathrm{CH} 4}$ values of interest; 38 are not research articles and are, for example, patents or book chapters and; 29 articles do not assess the production of $\mathrm{CH}_{4}$ from $\mathrm{AD}$, focusing on different 
technologies for manure-management systems (e.g. hydrogen production). All articles rejected by the second criteria correspond to review publications. The third criteria discards 14 articles that report titles and/or abstract in English, however, their main content was in a different language. In addition, 33 articles (from which 22 correspond to two journals), are not accessible to the authors. It should be noted that the database includes 45 scientific journals, thus, the third is not an important constraint. The fourth criteria rejects 178 papers that do not include numerical results on $Y_{C H 4}$ of $\mathrm{AD}$ process and 31 that use modelled or assumed (i.e. non-empirical) $Y_{C H 4}$ values. Regarding secondary variables that describe the typology of the studies, the origin and year of publication of the 115 selected articles are shown in Figure $2 \mathrm{~b}$ and Figure 3, respectively. It is observed that European and American work is dominant with 46 articles and 44 articles, respectively. For other continents markedly fewer articles are found to report empirical $Y_{C H 4}$ values. The categorisation of cases conforming the database according to world region is of particular interest when comparing results from this meta-analysis to the default maximum $Y_{C H 4}$ of the IPCC (see Section 3.5). -Figure 3 here-

With respect to year of publication, the literature covering $\mathrm{AD}$ of dairy cattle manure is increasing (see Figure 3). Results indicate that from 2007 to 2014 an average of 10 publication per year reported $Y_{C H 4}$ of dairy cattle manure. Before 2007 only two articles per year in average contain experimentally-measured $Y_{C H 4}$ of this dairy waste. This increase is expected because, although AD is a mature technology (i.e. implemented for waste treatment since 1880s in Europe [2]), today it is being re-visited as a mean to reduce carbon emissions in the context of international agreements. In addition, it is observed that the increase in publication begins the same year of the global financial crisis (2007-8), which could be related to dairy farms seeking to diversify their production activities. 
From the selected papers 2,181 cases are extracted and conform the database. To avoid duplicates, repeated cases found in five of the articles [25-29] are entered once. 2,161 of the cases in the database are selected from 95 articles. The remaining 20 articles report single cases from which 16 are identified as control experiments in co-digestion studies. Table 1 summarises secondary quantitative variables in the database according to digester type. It is observed that the cases in the database report different operation conditions and composition variables, according to the objectives of each article. For example, for batch and semi-continuous cases the time and hydraulic retention time, respectively, are specified in less cases than the temperature. However, for continuous digesters the opposite occurs. In order to improve the consistency in reporting the performance of $\mathrm{AD}$ systems in the research literature, it is recommended to follow standardised protocols such as the EPA Guidelines [30]. In consequence, the implementation of standardised protocols to report specifications on AD systems (and composition of inlet substrate) would allow the selection of a larger sample size for the multi-variate analysis of this work.

As presented in Table 1, 2,147 of the cases in the database can be classified as: batch, continuous or semi-continuous. The following sections analyse the $Y_{C H 4}$ and secondary quantitative variables separated in these categories. It should be noted that cases which report $Y_{C H 4}$ in units of measurements that cannot be reconciled to " $\mathrm{m}^{3} \mathrm{~kg}^{-1}$ ", are omitted.

\subsection{Batch digesters}

Batch reactors are the most reported in the literature for the AD of dairy cattle manure with 1,299 cases. From these, 1,144 cases from 54 articles report $Y_{C H 4}$ in the units of interest (or can be converted to it). Digesters operated as batch reactors are loaded at the beginning of the experiment (or cycle) and only biogas is extracted during the $\mathrm{AD}$ process. The yields from these digesters result in non-normal distribution (Shapiro's $\mathrm{P}=$ 
$3.06 \times 10^{-33}$ ), median $0.124 \mathrm{~m}^{3} \mathrm{~kg}^{-1}$ and inter-quartile range (IQR) $0.235 \mathrm{~m}^{3} \mathrm{~kg}^{-1}$. Low median is due to the presence of cases at low operation times, where the AD process is only beginning. In fact, 19 articles report profiles of $Y_{C H 4}$ against time, which indicate that multiple cases represent initial stages of $\mathrm{CH}_{4}$ production.

To observe underlying structure of the $Y_{C H 4}$ from batch digester, results from principal component analysis and their subsequent cluster analysis are shown in Figures 4a-b for operational and composition variables, respectively. For the former, 42 studies report simultaneously $Y_{C H 4}$, digester volume, temperature and operation time, yielding 1,104 cases. The first two principal components of Figure 4a represent jointly the variance fraction of $61.6 \%$. The first principal component is highly dependent on $Y_{C H 4}$ and time of operation, while the contrary is observed for the second principal component. -Figure 4 here-

The directions of the $Y_{C H 4}$ and time of residency vectors are similar. Thus, high $Y_{C H 4}$ are associated to longer digestion times, as expected. Higher correlation is also expected $\left(\right.$ Spearman's rho $=0.411, \mathrm{P}$-value $\left.=2.2 \times 10^{-16}\right)$, but not achieved due to the presence of overlapping profiles (i.e. see bi-plots of $Y_{\mathrm{CH} 4}$ over time in Supporting Material). Individual profiles of $Y_{C H 4}$ are observed to reach asymptotic maximums. This is due to decrease in the available organic material to be anaerobically digested. As time advances in batch digesters, bacterial population growth is limited by the availability of nutrients and therefore, these profiles are associated to Monod's equation [31]. With respect to the digester volume, the $Y_{C H 4}$ vector shows opposite direction (with respect to the first principal component axis), which can be attributed to variables presenting poor (and negative) correlation (Spearman's rho $=-0.135, \mathrm{P}$-value $=$ $\left.4.68 \times 10^{-6}\right)$. It is unexpected that the temperature vector is opposite to the $Y_{C H 4}$, with respect to the first principal component axis. Much work (e.g. Umetsu et al. [32] and Kaparaju et al. [33]) have reported an increase of $Y_{C H 4}$ with raise of temperature, 
however, the batch digesters collected in the database show a weak and inverse correlation (Spearman's rho $=-0.263, \mathrm{P}$-value $=2.2 \times 10^{-16}$ ). This could be explained by batch digesters achieving maximum $Y_{\mathrm{CH} 4}$ independently of operation temperature as long as enough retention time is allowed.

Four clusters result from the k-means algorithm $(\mathrm{DB}$ Index $=0.25)$, as shown in Figure 4a. All clusters extend across the first principal component, while being less affected by the second principal component. The red cluster of Figure 4a, corresponds to small digesters $(0.30-2.0 l)$ operating at the highest temperatures for batch digesters in the database $\left(50{ }^{\circ} \mathrm{C}\right.$ and $\left.55{ }^{\circ} \mathrm{C}\right)$. This cluster is conformed by 73 cases from seven articles. The blue cluster of Figure 4a, represents large digesters $(850 l)$ operating at $35{ }^{\circ} \mathrm{C}$. This cluster of 34 cases is conformed by the data reported in only one article [34]. Both blue and red clusters correspond to the lower $Y_{C H 4}$ obtained for batch digesters with maximums 0.19 and $0.29 \mathrm{~m}^{3} \mathrm{~kg}^{-1}$, respectively. The green and yellow clusters of Figure 4a correspond to the most common values for digester volumes (0.1 to $5.0 l$ ) and temperatures $\left(25\right.$ to $38{ }^{\circ} \mathrm{C}$ ). These clusters are conformed by 653 cases (from 31 articles) and 344 cases (from 24 articles), respectively. The main difference between these groups is the time of reaction. In particular, the green cluster represents experiments carried out at lower retention times (up to $69 d$ ) than those in the yellow cluster (up to $160 d$ ). In agreement with this, the centroid of the green cluster corresponds to a lower $Y_{C H 4}$ $\left(\sim 0.05 \mathrm{~m}^{3} \mathrm{~kg}^{-1}\right)$ than that of the yellow cluster $\left(\sim 0.32 \mathrm{~m}^{3} \mathrm{~kg}^{-1}\right)$. An interesting case in the yellow cluster is that of Zeeman et al. [35] which, although outside the main group of cases, shows high $Y_{\mathrm{CH} 4}\left(0.11 \mathrm{~m}^{3} \mathrm{~kg}^{-1}\right)$ for low operation temperature $\left(25^{\circ} \mathrm{C}\right)$. For secondary variables describing initial compositions, only 4 studies report simultaneously $Y_{C H 4}, \mathrm{pH}, \mathrm{DM}$ content, VS content and COD values, yielding 108 cases. The first two principal components of these variables are shown in Figure $4 \mathrm{~b}$ and represent the variance fraction of $74.8 \%$. The variables that most affect the first 
principal component (variance fraction of $51.8 \%$ ) are VS, DM and COD. These variables relate to the available organic matter to be digested, thus, their vectors in Figure $4 \mathrm{~b}$ are in similar direction. DM and COD present weak negative correlations with respect to $Y_{C H 4}$ resulting in Spearman's rho of $-0.361\left(\mathrm{P}\right.$-value $\left.=6.3 \times 10^{-18}\right)$ and -0.261 for $\mathrm{COD}\left(\mathrm{P}-\mathrm{value}=2.5 \times 10^{-9}\right)$, respectively. VS shows a moderate monotonic function (Spearman's rho $=-0.457$ and P-value $=1.6 \times 10^{-27}$ ). The second principal component is more affected by $\mathrm{pH}$ and $Y_{C H 4}$. These vectors show a strong negatively correlation (Spearman's rho $=-0.6960, \mathrm{P}$-value $=1.0 \times 10^{-97}$ ), which is reflected in the opposite direction of their vectors in Figure 4b. This is an expected result because high $\mathrm{pH}$ content (e.g. ammonia in the slurry) can inhibit the methanogenic activity [36]. Eight clusters result $(\mathrm{DB}$ Index $=0.13)$ from the k-mean applied to the principal components of composition variables for batch digesters. The cases align in diagonals which could suggest that other cluster algorithms are preferable (e.g. density-based). The particular large amount of clusters for this bi-plot could be due to overlapping data in each diagonal which can affect the DB Index optimisation [37]. The lines which arise from the cases are parallel with slope value -1.56. In the case of the yellow and light blue clusters, these align having $\mathrm{pH} 6.8, \mathrm{DM}$ mass fraction 1.9\%, VS dry mass fraction $62.7 \%$ and COD $21 \mathrm{~kg} \cdot \mathrm{m}^{-3}$. The $Y_{\mathrm{CH} 4}$ for these clusters ranges from 0 to $0.33 \mathrm{~m}^{3} \mathrm{~kg}^{-1}$. Their intercept is 1.17. The orange, blue and red clusters (bottom right of Figure $4 \mathrm{~b}$ ) are aligned with an intercept -3.09 . The cases in these clusters, have fix value for $\mathrm{pH}$ (6.5), DM (mass fraction 2.3\%), VS (dry mass fraction $74.7 \%)$ and COD $\left(30.3 \mathrm{~kg} \cdot \mathrm{m}^{-3}\right)$. The red cluster corresponds to a case from the work of Pandey et al. [38], who attribute the high results to differences in the inocula utilised (i.e. granular sludge from digester processing potato starch). However, it is considered to be an outlier in this meta-analysis because it reports $1.67 \mathrm{~m}^{3} \mathrm{~kg}^{-1}$ for $Y_{\mathrm{CH} 4}$, markedly exceeding the theoretical value $\left(0.469 \mathrm{~m}^{3} \mathrm{~kg}^{-1}\right.$ by Buswell's equation $\left.[39,5]\right)$. 
The light green cluster has $\mathrm{pH} 6.9$, DM mass fraction 5.3\%, VS dry mass fraction $73.6 \%$ and COD $70.3 \mathrm{~kg} \cdot \mathrm{m}^{-3}$, with $Y_{\mathrm{CH} 4}$ ranging from 0.26 to $0.33 \mathrm{~m}^{3} \mathrm{~kg}^{-1}$. The parallel that crosses this cluster has an intercept -5.78 . The final cluster corresponds to a single case from Pabon-Pereira [40] (dark green cluster in Figure 4b). This has pH 6.9, DM mass fraction $10.5 \%$, VS dry mass fraction $86.7 \%$ and COD $29.2 \mathrm{~kg} \cdot \mathrm{m}^{-3}\left(Y_{\mathrm{CH} 4}\right.$ range $=0.14$ to $0.23 \mathrm{~m}^{3} \mathrm{~kg}^{-1}$ ). If the same slope was repeated for this case, the intercept is -10.6. Overall, an increase in the organic matter content of the slurry is observed according to the first principal component. However, the increase of these variables presents no correlation with the ranges of $Y_{C H 4}$ in each aligned group. This also is observed by the low correlations (i.e. Spearman rho values) between $Y_{C H 4}$ and DM, VS and COD.

\subsection{Continuos digesters}

Continuous and semi-continuous digesters are less found in the literature in comparison to batch systems. The $Y_{C H 4}$ distributions for these types of digesters are shown as green box-plots in Figure 5. The orange box-plot correspond to distribution of $Y_{\mathrm{CH} 4}$ which are jointly reported with $N_{i}$ and $s_{i}$, thus, can be used for meta-analysis. The results from meta-analyses models are also presented in Figure 5 (fixed-effect model: red circles and random-effect model: yellow circles).

\section{-Figure 5 here-}

The database includes 335 cases for continuous digesters (see Table 1), from which 331 (from 38 articles) are used because $Y_{C H 4}$ can be expressed as " $\mathrm{m}^{3} \mathrm{~kg}^{-1}$ ". For these digesters, dairy cattle manure is fed continuously into the reactor while streams of biogas and digestate (products) are removed. Specific subcategories found for continuous digesters, according to reactor operation are (see Figure 5): continuously-stirred tank reactors (CSTRs), fixed-film reactors, plug-flow reactors and up-flow anaerobic sludge blanket. 
There are 241 cases (from 35 articles) in the database that report $Y_{C H 4}$ from CSTR. The distribution of all $Y_{\mathrm{CH} 4}$ for this digester type (green boxplot in Figure 5) is non-normal (Shapiro's $\mathrm{P}=2.91 \times 10^{-5}$ ) and has a median $0.141 \mathrm{~m}^{3} \mathrm{~kg}^{-1}$. As expected this distribution is significantly lower (Wilcox's $\mathrm{P}=2.97 \times 10^{-16}$ ) from the $B_{0}$ of batch digesters. This is due to significantly lower hydraulic retention times (HRTs) in continuous digeseters compared to residency time in batch digesters (Wilcox's $\mathrm{P}<$ $2.2 \times 10^{-16}$ ). From this distribution, 12 cases report $Y_{C H 4}$ with $N_{i}$ and $s_{i}$ (orange box-plots in Figure 5). This subgroup is non-significantly different from the distribution of all $Y_{C H 4}$ reported for CSTR (Wilcox's $\mathrm{P}=0.143$ ). Therefore, meta-analysis models applied over this subgroup are representative of the literature data. The meta-analyses models applied over the latter cases results in $0.179 \pm 0.001 \mathrm{~m}^{3} \mathrm{~kg}^{-1}$ for fixed-effects and $0.190 \pm 0.016 \mathrm{~m}^{3} \mathrm{~kg}^{-1}$ for random-effects. Multi-variate analysis is carried out for CSTRs because these are the most numerous cases reported for continuous digesters. Score-plots for operation variables associated with CSTR digesters are shown in Figure 4c. From 23 articles which report all operation variables of Table 1, 173 cases are extracted and used for principal component analysis. The first principal component of Figure 4c corresponds to the variance fraction of $43.2 \%$ and is highly dependent on $Y_{C H 4}$, OLR and volume. Contrary to batch digesters, the volume and temperature vectors are in the same direction as the $Y_{C H 4}$ with respect to the first principal component. These both variables show a strong positive correlation with respect to $Y_{C H 4}$ (Spearman's rho= 0.71 for volume and; rho= 0.69 for temperature). The second principal component represents the variance fraction of $26.8 \%$ and is mostly affected by the HRT and OLR. A positive moderate correlation (Spearman's rho $=0.435$, P-value: $2.7 \times 10^{-16}$ ) is found, between the $Y_{C H 4}$ and HRT. At lower HRT $(<40 d), Y_{C H 4}$ exhibits a larger range $\left(0.002\right.$ to $\left.0.333 \mathrm{~m}^{3} \mathrm{~kg}^{-1}\right)$, while presenting more stable values thereafter. These observations are similar to the 
asymptotic profiles for $Y_{\mathrm{CH} 4}$ and retention time in batch digesters (see biplots of Supporting Material). With respect to the OLR, the $Y_{C H 4}$ vector is in opposite direction having a Spearman's rho $-0.45\left(\mathrm{P}\right.$-value $\left.=5.2 \times 10^{-11}\right)$. This is an expected result because increasing OLR (i.e. lowering the retention times) can wash-out bacterial cultures reducing the digester performance [41].

Two clusters are output from the application of k-means to the principal components of Figure 4c (DB Index $=0.37)$. The blue cluster is conformed by 95 cases from 16 articles. This cluster groups cases in a larger range of HRT ( 1 to $128 d$ ) and OLR (0.12 to 34.4 $\mathrm{kg} \cdot \mathrm{m}^{-3} \mathrm{~d}^{-1}$ ), compared to the green cluster (HRT: 8 to $69 d$ and; OLR: 0.12 to 6.6 $\left.\mathrm{kg} \cdot \mathrm{m}^{-3} \mathrm{~d}^{-1}\right)$. The digesters operating within the blue cluster also have lower temperatures $\left(10\right.$ to $55{ }^{\circ} \mathrm{C}$ ) and result in lower $Y_{C H 4}$ (maximum $0.220 \mathrm{~m}^{3} \mathrm{~kg}^{-1}$ ). For the green cluster, 78 cases (from 11 articles) are observed in Figure 4c. The $Y_{C H 4}$ from cases in this cluster range from 0.115 to $0.333 \mathrm{~m}^{3} \mathrm{~kg}^{-1}$. In general, these cases operate at higher temperatures $\left(35\right.$ to $55^{\circ} \mathrm{C}$ ) and in larger digesters (up to $1,500 l$ ) than those in the blue cluster (up to $230 l$ ).

With regards to the composition variables (see Table 1), it is found that there are insufficient cases of CSTR digesters in the literature for dairy cattle manure to perform principal component analysis. However, there are enough cases for bi-variate analysis between $Y_{C H 4}$ and each composition variable (see Supplementary Material). The variables most correlated with $Y_{C H 4}$ are found to be the $\mathrm{pH}$ (Spearman's rho= $-0.685, \mathrm{P}$-value $=2.0 \times 10^{-15}$ ) and nitrogen content (i.e. TKN, Spearman's rho $=0.605$, $\mathrm{P}$-value $\left.=7.8 \times 10^{-13}\right)$ of untreated manure. The strong correlation between $\mathrm{pH}$ and $Y_{C H 4}$ is in agreement with the findings for batch digesters. However, high correlation between TKN and $Y_{C H 4}$ is unexpected because higher nitrogen in ammonia has been reported to inhibit AD [36]. For variables related to organic material in the input slurry, only weak correlations are found with respect to $Y_{C H 4}$ : DM (Spearman's rho= 0.188 , 
$\mathrm{P}$-value $=0.018), \mathrm{VS}$ (Spearman's rho $=-0.338, \mathrm{P}$-value: $\left.2.5 \times 10^{-5}\right)$ and COD $\left(\right.$ Spearman's rho $=0.48, \mathrm{P}$-value $\left.=1.9 \times 10^{-8}\right)$.

Fixed-film reactors are the second most numerous continuous digesters collected in the database ( $\mathrm{N}=81$, from five articles). The $Y_{\mathrm{CH} 4}$ for this digester type (green boxplot in Figure 5) is not normally distributed (Shapiro's $\mathrm{P}=3.3 \times 10^{-14}$ ) and has median 0.103 $\mathrm{m}^{3} \mathrm{~kg}^{-1}$. From these $Y_{\mathrm{CH} 4}$, eight cases from the work of Lo et al. [27] are the only to report $N_{i}$ and $s_{i}$ (orange box-plot Figure 5). The fixed-effect meta-analysis model applied over these eight cases results in $Y_{C H 4}$ mean of $0.017 \pm 0.001 \mathrm{~m}^{3} \mathrm{~kg}^{-1}$. For the random-effect model, the mean $Y_{C H 4}$ is $0.018 \pm 0.006 \mathrm{~m}^{3} \mathrm{~kg}^{-1}$. However, the means obtained by meta-analysis should be used with caution as the distribution of the eight cases in the subgroup is significantly different (Wilcox's $\mathrm{P}=3.94 \times 10^{-4}$ ) from the $Y_{\mathrm{CH} 4}$ in the 81 cases for all plug-flow digesters in the database.

For the remaining continuous digesters, insufficient cases are collected for the application of meta-analysis models. A single case is found to report experimental $Y_{C H 4}$ of dairy cattle manure in units of interest for plug-flow reactors (PFRs, N=1). Thus, the latter is ommited from Figure 5). For up-flow anaerobic sludge blanket (UASB) digesters, there are eight cases which report experimental $Y_{C H 4}$ and correspond to the work of Rico et al. [42]. The distribution of these digesters is normal (Shapiro's $\mathrm{P}=$ 0.58 ) and has median $0.484 \mathrm{~m}^{3} \mathrm{~kg}^{-1}$ (see Figure 5). The mean of these cases, exceeds the theoretical value $\left(0.469 \mathrm{~m}^{3} \mathrm{~kg}^{-1}\right.$ by Buswell's equation [39, 5]). However, they do not present a significant difference (Wilcox's P-value $=1$ ). Therefore, differences in $Y_{C H 4}$ could be attributed to chemical compositions or longer biomass retention time (i.e. bacterial consortia and organic substrate).

\subsection{Semi-continuos digesters}

For semi-continuous digesters the input and/or output of digesters are discontinuous. There are 513 of these cases identified in this work (Table 1) and 443 of them (from 26 
studies) are used.

One type of semi-continuous digester corresponds to AD ponds. These usually accumulate manure periodically but are discharged sporadically (e.g. when the produced bio-fertiliser is needed). There are 96 cases identified in the database for lagoon digesters from three articles. The high variability in loading/discharging rates and operation temperature results in a large IQR of $0.214 \mathrm{~m}^{3} \mathrm{~kg}^{-1}$ (see Figure 5). The $Y_{C H 4}$ for lagoon digesters presents a non-normal distribution (Shapiro's $\mathrm{P}=2.84 \times 10^{-6}$ ) and median $0.345 \mathrm{~m}^{3} \mathrm{~kg}^{-1}$. This median is not significantly different than the theoretical $Y_{C H 4}$ (Wilcox's P-value $=0.422$ ). The higher $Y_{C H 4}$ of the lagoon digesters distribution, has been attributed by other authors [43-45] to degradation of accumulated organic matter on the bottom of ponds. Thus, more VS are available to be converted to $\mathrm{CH}_{4}$, than the measured at the inlet to the AD ponds. From the above, it is suggested that for future work, measurements of VS fed to lagoon digesters are standardised. From the 96 cases, only two (from two articles [43, 44]) can be used for meta-analysis models (orange box-plot in Figure 5). The $Y_{\mathrm{CH} 4}$ of these cases is non-significantly different from the distribution of all lagoon digesters (Wilcox's $\mathrm{P}=0.297$ ). The fixed effect model results in a mean $0.400 \pm 0.057 \mathrm{~m}^{3} \mathrm{~kg}^{-1}$ (see red circles of Figure 5). This is in great agreement with the case from Safley et al. [43], because the sample size of $Y_{C H 4}$ from that case is 93, whereas, the case from Park et al. [44] has a sample size of seven. For the random-effect model a mean of $0.440 \pm 0.160 \mathrm{~m}^{3} \mathrm{~kg}^{-1}$ is obtained. There are 347 cases in the database (from 23 articles) that include $Y_{C H 4}$ from other non-specified semi-continuous digesters. These cases are grouped and also shown in Figure 5. Their distribution is non-normal (Shapiro's $\mathrm{P}<2.2 \times 10^{-16}$ ) with median 0.173 $\mathrm{m}^{3} \mathrm{~kg}^{-1}$. A subgroup of 27 of these cases (from five articles) are utilised for meta-analysis models. For the fixed-effect model a mean $0.176 \pm 0.001 \mathrm{~m}^{3} \mathrm{~kg}^{-1}$ is obtained and for the random-effect model $0.204 \pm 0.032 \mathrm{~m}^{3} \mathrm{~kg}^{-1}$. 
There are 98 cases from 15 articles in the database that specify all operation variables of Table 1 and $Y_{C H 4}$, for semi-continuous digesters (non-specified, i.e. anaerobic digesters labelled as ponds are excluded). These cases undergo principal component analysis and the resulting score-plots are presented in Figure 4d. With the excpetion of the volume vector, it is observed that according to the variables directions (red arrows of Figure 4d), the semi-continuous digesters are in closer agreement to the batch digesters than the continuous digesters. In fact, it is observed that the studies utilising semi-continuous digesters are classified as such because of the feeding procedure, however, the overview of many systems corresponds to dynamic states, rather than stationary (i.e. continuously operated digesters).

The first principal component represents the variance fraction of $43.7 \%$ and the second $27.8 \%$. The first principal component is highly dependent on OLR and $Y_{C H 4}$ and exhibit a weak correlation (Spearman's rho $=-0.262 ; \mathrm{P}-$ value $=1.0 \times 10^{-5}$ ). The second principal component is mostly affected by the volume and temperature. The direction of the $Y_{C H 4}$ vector is opposite (along the first principal component axis) to the digester temperature. This shows a weak and inverse correlation which is further indicated by the Spearman's rho value $-0.162\left(\mathrm{P}\right.$-value $\left.=2.6 \times 10^{-3}\right)$. The volume of digesters also presents a weak negative correlation to the $Y_{\mathrm{CH} 4}$ (Spearman's rho=-0.250;

P-value $\left.=2.5 \times 10^{-6}\right)$. Regarding the HRT and $Y_{C H 4}$ vectors, these have similar direction, with respect to the first principal component. These variables exhibit a moderate positive correlation (Spearman's rho $=0.242, \mathrm{P}$-value $=5.1 \times 10^{-6}$ ) and follow similar patterns than those observed for batch digester (see Supporting Material). Three clusters are found $(\mathrm{DBI}=0.33)$ for semi-continuous digesters and presented in Figure 4d. The red cluster comprises 28 cases from three different articles of Lo et al. (see online database). It is observed that all cases in the cluster operate at thermophilic conditions $\left(55^{\circ} \mathrm{C}\right)$ and volume $3 l$. The differences in principal components for this 
cluster are due to changes in OLR $\left(2.07\right.$ to $\left.35 \mathrm{~kg} \cdot \mathrm{m}^{-3} \mathrm{~d}^{-1}\right)$ and HRT (1 to $\left.15 d\right)$. The $Y_{C H 4}$ range is the lowest among those in Figure 4d, from 0.011 to $0.161 \mathrm{~m}^{3} \mathrm{~kg}^{-1}$. The blue cluster comprises 57 cases from 13 articles. These cases exhibit higher $Y_{C H 4}$ than the red cluster, with centroid at approximately $0.262 \mathrm{~m}^{3} \mathrm{~kg}^{-1}$. This is attributed to higher HRT $\left(1\right.$ to $60 d$ ) and, in turns, lower OLR $\left(0.4\right.$ to $\left.8.87 \mathrm{~kg} \cdot \mathrm{m}^{-3} \mathrm{~d}^{-1}\right)$. The semi-continuous digesters of the blue cluster operate at the lowest range of temperatures $\left(20\right.$ to $37^{\circ} \mathrm{C}$ ), which is consistent with psychrophilic and mesophilic conditions. The volumes of the digesters in this cluster covers a large range (between $0.04 \mathrm{~L}$ and $300 \mathrm{~L}$ ), suggesting that this operation variable is not affecting the principal components describing AD performance. The green cluster of Figure 4d corresponds to 13 cases from two articles. The $Y_{C H 4}$ are the highest found for the semi-continous digesters, with centroid at approximately $0.77 \mathrm{~m}^{3} \mathrm{~kg}^{-1}$. This exceeds batch performances, which could suggest the presence of lagoons which, as discussed previously (see Figure 5), have been identified to have higher performance due organic material accumulated in the bottom of digesters. The OLR $\left(0.5\right.$ to $\left.2.9 \mathrm{~kg} \cdot \mathrm{m}^{-3} \mathrm{~d}^{-1}\right)$ and HRT $(10-20 d)$ is not markedly different from the other clusters. The temperatures of the digesters in the green cluster are between 35 and $45{ }^{\circ} \mathrm{C}$ (i.e. mesophilic conditions). This suggests that temperature is a key factor in the separation of the three clusters. As for continuous digesters, there are insufficient cases of semi-continuos reactors in the database to perform principal component analysis over composition variables of interest. Considering bi-variate analysis some moderate correlations can be found between $Y_{C H 4}$ and secondary variables describing initial composition of the dairy cattle manure. The strongest correlations between $Y_{\mathrm{CH} 4}$ and a secondary variable is with COD (Spearman's rho $=-0.542, \mathrm{P}$-value $=2.2 \times 10^{-16}$ ) and TKN (Spearman's rho $=-0.485$, P-value $=$ $\left.1.6 \times 10^{-13}\right)$. This interesting result supports the well-known work of Angelidaki et al. [36], which reports that an increase in ammonia (containing nitrogen) can suppress $\mathrm{CH}_{4}$ 
production in $\mathrm{AD}$ of livestock waste. However, it should be noted that Sterling et al. [46] have reported that only large increases in ammonia can inhibit AD, while gradual increases could enhance the $\mathrm{CH}_{4}$. The latter is not evidenced in the results of this work. The other composition variables of interest are less correlated or weakly correlated to $Y_{C H 4}: \mathrm{pH}$ (Spearman's rho= $\left.-0.060, \mathrm{P}-\mathrm{value}=0.41\right), \mathrm{DM}$ (Spearman's rho $=-0.354$, $\mathrm{P}$-value $\left.=2.8 \times 10^{-9}\right)$ and VS (Spearman's rho $=-0.284, \mathrm{P}$-value $\left.=3.5 \times 10^{-6}\right)$.

\subsection{Maximum methane potentials}

This section considers the experimental $Y_{C H 4}\left(B_{0}\right)$ of dairy cattle manure (i.e. obtained from batch essays). These values are interesting to study separately from other cases, because they can be utilised to quantify energy output and environmental benefits of AD systems. Much work is based on the methodology described by Owen et al. [47] to experimentally determine $B_{0}$. However, it should be noted that there is little agreement in the use of this or any standard protocol [48]. This results in difficulties to identify the differences between $\mathrm{AD}$ systems. In particular, an essential issue to consider when comparing $B_{0}$ from different $\mathrm{AD}$ systems is to report the temperature and pressure at which the experiments are carried out (i.e. as reported by Marti-Herrero et al. [49]). The $B_{0}$ from the database are used to obtain novel effect sizes by meta-analysis models . Results are compared against the $B_{0}$ default values from the IPCC 2006 methodology [15], in accordance to the world regions defined in the latter.

The IPCC Guidelines provide two default values of $B_{0}$ from AD of dairy cattle manure. For Europe, Oceania and North America the default $B_{0}$ is $0.24 \mathrm{~m}^{3} \mathrm{~kg}^{-1}$ and is based on the work of Morris $1976[50,15]$. For other regions of the world the default value 0.13 $\mathrm{m}^{3} \mathrm{~kg}^{-1}$ is based on the work of Safley et al. $(1992,[51,15])$. A revision of these values is needed because they only consider a reduced amount of literature (from 1976 and 1992) and exclude the last thirteen years of research which, according to the findings of this work (see Figure 3), accounts for the fraction of $87.5 \%$ of published articles in the 
field. Furthermore, the $B_{0}$ of the original work is based on the diet of dairy cattle which are also in need of update.

The $B_{0}$ values from the IPCC are shown as blue circles in Figure 6 . It should be noted that these default $Y_{C H 4}$ are not considered in the subgroup for meta-analysis because the original sources $[51,50]$ are published in books (i.e. not research articles as required by the first criterion).

-Figure 6 here-

From the database, 799 cases (from 42 articles) are identified as either biochemical potential tests or maximum $Y_{\mathrm{CH} 4}$ determined in similar batch conditions (i.e. measuring cumulative $\mathrm{CH}_{4}$ production until no increase is observed). For articles reporting $Y_{\mathrm{CH} 4}$ against time, the maximum yield of each profile is extracted. In the 42 articles, 143 cases are identified as $B_{0}$. The distributions of $B_{0}$ are represented by the green box-plots of Figure 6. For all the regions defined in the IPCC Guidelines experimental results (in comparable units of measurements) are found for $B_{0}$ (see number of cases in Table 3), except Oceania and Latin America (i.e. omitted in Figure 6). As expected, the results for $B_{0}$ are significantly higher than the $Y_{C H 4}$ distribution for all batch cases (Wilcox's $\mathrm{P}=9.67 \times 10^{-10}$ ).

-Table 3 here-

It is observed in Figure 6, that the $B_{0}$ values from the IPCC with corresponding error bars of $15 \%$, are within the distribution of $B_{0}$ found in the database. In fact, only the region comprising Asia, Middle East and Indian Subcontinent shows a significant difference (Wilcox's P-values in Table 3 ) in $B_{0}$ distribution with respect to the IPCC value. This could be attributed to developments in feeding of dairy cattle in that region, because the IPCC default values are based on the dairy diets prior to 1992 [51]). Similar observations are found for African experiments (i.e. the fraction of cases which is greater than the default IPCC value is $60 \%$ ). However, the sample size is not large 
enough $(\mathrm{N}=5)$ to prove significant difference. Europe and North America present the largest samples of $B_{0}$ (see Table 3), as expected from the origin of the articles identified in Section 3.1.

Although most regional $B_{0}$ values are non-significantly different from those in the database from the IPCC default values, results indicate that different means and error bars would better represent the findings of the literature. Therefore novel effect sizes and confidence intervals are examined by applying fixed- and random-effect models of meta-analysis.

The meta-analysis models require cases which report $B_{0}$ together with specific $N_{i}$ and $s_{i}$. For this 53 cases from 21 studies are selected. The distributions of this subgroup of $B_{0}$ is shown in Figure 6 (orange box-plots). Results show that the means of these distribution differ with the IPCC default value between 0.01 and $0.13 \mathrm{~m}^{3} \mathrm{~kg}^{-1}$. In particular, the subgroup distributions for the Asia, Middle East \& Indian Subcontinent Region is again the only significantly different $(\mathrm{p}<0.05)$ from the IPCC value (i.e. as for the green box-plot of Figure 6, discussed previously).

The results of fixed-effect and random-effect models are also shown in Figure 6 in red and yellow circles, respectively. The means obtained by the random-effect models are found to be in best agreement with the distributions of the subgroup of $B_{0}$ cases (i.e. case reporting $N_{i}$ and $s_{i}$ ), with differences from 0.001 to $0.026 \mathrm{~m}^{3} \mathrm{~kg}^{-1}$. The means for this model are $0.230 \pm 0.016,0.230 \pm 0.047,0.230 \pm 0.020,0.260 \pm 0.060$ and $0.110 \pm 0.022 \mathrm{~m}^{3} \mathrm{~kg}^{-1}$ for all regions, Asia/Middle East \& Indian Subcontinent, West/East Europe, North America and Africa, respectively. For the fixed-effect model the means are $0.198 \pm 0.001,0.220 \pm 0.003,0.195 \pm 0.001,0.280 \pm 0.011,0.100 \pm 0.009$ $\mathrm{m}^{3} \mathrm{~kg}^{-1}$, for the same regions mentioned above, respectively. This results in differences from 0.010 to $0.040 \mathrm{~m}^{3} \mathrm{~kg}^{-1}$ between the means of the fixed-effect model and those of the subgroup of $B_{0}$ cases. The random-effect model is expected to show better results 
because it assumes a distribution of $B_{0}$, rather than a fix value. This is more representative of the high heterogeneity of the samples, which arise from different experimental set-ups. Therefore, it is preferable to adopt the results of $B_{0}$ from the random-effect model to estimate the potential $\mathrm{CH}_{4}$ production from $\mathrm{AD}$ of dairy manure.

Compared to the IPCC default values, the random-effect meta-analysis model provides more robust values of $B_{0}$ (i.e. based on larger sample size, more updated cases and considers the heterogeneity of cases). Therefore, the means and confidence intervals of $B_{0}$ obtained by this model are suggested to replace those in the current IPCC Guidelines. Furthermore, it is recommended to apply this meta-analysis model for the estimation of $B_{0}$ of other digestible feedstock. This would provide better IPCC-default $B_{0}$ values, with stronger evidence-base (i.e. larger sample integration).

\section{Conclusions}

This work presents a meta-analysis of methane yield of dairy cattle manure. A novel database is compiled from 115 selected articles (2,181 cases). The systematic review of the literature shows that the report of operation conditions and slurry composition does not generally follow standardised protocols. The latter are strongly recommended in order to provide insights of differences in performance of AD systems.

Meta-analysis models are applied over the database according to digester type (batch, continuous or semi-continuous). This methodology enables numerical combination and synthesis of experimental results to date.

Multi-variate analysis identifies clusters for $Y_{C H 4}$ and operation conditions (i.e. temperature, volume, time/HRT, OLR) or feedstock composition (i.e. pH, DM, VS, COD, TKN). This can contribute to the construction of AD scenarios by providing ranges of variables that are commonly grouped. 
Meta-analysis applied over maximum $Y_{\mathrm{CH} 4}$ is a reliable form to correct the out-of-date IPCC default values. This method has a greater sample size (i.e. based on more articles than the current IPCC Guidelines). Consequently, this work can contribute to more robust estimates of energy production and greenhouse gas mitigation of AD systems in the dairy sector.

\section{Supporting Material}

Supporting information containing biplots for $Y_{C H 4}$ against secondary quantitative variables and DB Index results is available online.

\section{Acknowledgements}

The authors would like to acknowledge Becas Chile (call of 2010) for funding the first author of this work. 


\section{References}

[1] Food and Agriculture Organization of the United Nations, Animal Production and Health Division. Greenhouse Gas Emissions from the Dairy Sector a Life Cycle Assessment. Rome: FAO; 2010.

[2] Deublein D, Steinhauser A. Biogas from Waste and Renewable Resources. 2nd ed. Weinheim, Germany: Wiley; 2010.

[3] Berglund M, Barjesson P. Assessment of energy performance in the life-cycle of biogas production. Biomass Bioenerg. 2006;30(3):254-66.

[4] Buswell AM. Anaerobic Fermentators. Urbana, Illinoise: Division of the State Water Survey, State of Illinois; 1936.

[5] Symons GE, Buswell AM. The methane fermentation of carbohydrates. J Am Chem Soc. 1933;55(5):2028-36.

[6] Page DI, Hickey KL, Narula R, Main AL, Grimberg SJ. Modeling anaerobic digestion of dairy manure using the IWA Anaerobic Digestion Model No. 1 (ADM1). Water Sci Technol. 2008;58(3):689-95.

[7] Linke B. A model for anaerobic digestion of animal waste slurries. Environ Technol. 1997;18(8):849-54.

[8] Menten F, Chèze B, Patouillard L, Bouvart F. A review of LCA greenhouse gas emissions results for advanced biofuels: The use of meta-regression analysis. Renewable Sustainable Energy Rev. 2013;26:108-34.

[9] Farrell AE, Plevin RJ, Turner BT, Jones AD, O'Hare M, Kammen DM. Ethanol can contribute to energy and environmental goals. Science. 2006;311(5760):506-8. 
[10] Van der Meer HG. Optimising manure management for GHG outcomes. Aust J Exp Agric. 2008;48(1-2):38-45.

[11] Massa DI, Talbot G, Gilbert Y, Massé DI. On farm biogas production: A method to reduce GHG emissions and develop more sustainable livestock operations. Anim Feed Sci Technol. 2011;166:436-45.

[12] Novak SM, Fiorelli JL. Greenhouse gases and ammonia emissions from organic mixed crop-dairy systems: a critical review of mitigation options. Agron Sustainable Dev. 2010;30(2):215-36.

[13] Nelson MC, Morrison M, Yu Z. A meta-analysis of the microbial diversity observed in anaerobic digesters. Bioresour Technol. 2011;102(4):3730-9.

[14] Miranda ND, Tuomisto HL, McCulloch MD. Meta-analysis of GHG emissions from anaerobic digestion processes in dairy farms. Environ Sci Technol. $2015 ; 49(8): 5211-9$.

[15] Intergovernmental Panel of Climate Change (IPCC). Guidelines for National Greenhouse Inventories. Volume 4: Agriculture, Forestry and Other Land Use. Hayama: IPCC National Greenhuse Gas Inventories Programme; 2006.

[16] ISI Web of Knowledge [homepage on the Internet]. Search Engine Online Resource. Thomson Reuters; [cited 2015 Feb 18] Available from: http://www.isiwebofknowlege.com/.

[17] Deng Y, Xu J, Liu Y, Mancl K. Biogas as a sustainable energy source in China: Regional development strategy application and decision making. Renew Sustain Energy Rev. 2014;35:294-303. 
[18] Rao PV, Baral SS, Dey R, Mutnuri S. Biogas generation potential by anaerobic digestion for sustainable energy development in India. Renew Sustain Energy Rev. 2010;14(7):2086-94.

[19] Shapiro SS, Wilk MB. An analysis of variance test for normality (complete samples). Biometrika. 1965;52(3/4):591-611.

[20] Wilcoxon F. Individual Comparisons by Ranking Methods. Biometrics Bull. $1945 ; 1(6): 80-3$.

[21] Spearman C. The proof and measurement of association between two things. Am J Psychol. 1904;15(1):72-101.

[22] Brambilla M, Araldi F, Marchesi M, Bertazzoni B, Zagni M, Navarotto P. Monitoring of the startup phase of one continuous anaerobic digester at pilot scale level. Biomass Bioenerg. 2012;36:439-46.

[23] Henderson P, Seaby R. A Practical Handbook for Multivariate Methods. Pennington, UK: Pisces Conservation; 2008.

[24] Gan G, Ma C, Wu J. Data Clustering: Theory, Algorithms, and Applications. 1st ed. Philadelphia: Society for Industrial and Applied Mathematics; 2007.

[25] Lo KV, Liao PH, Bulley NR, Chieng ST. A comparison of biogas production from dairy manure filtrate using conventional and fixed-film reactors. Can Agric Eng. $1984 ; 26(1): 73-8$.

[26] Lo KV, Liao PH. Psychrophilic Anaerobic Digestion of Screened Dairy Manure. Energy Agric. 1985;5(4):339-46.

[27] Lo KVV, Liao PHH, March AC. Thermophilic anaerobic digestion of screened dairy manure. Biomass. 1985;6(4):301-15. 
[28] Lo KV, Liao PH, Whitehead AJ. Methane production at 22 celsius of laboratory-scale fixed-film reactors receiving screened dairy manure. Energy Agric. 1985;4(1):1-14.

[29] Lo KV, March AC, Liao PH. Determination of optimal feed strength for the thermophilic production of methane from dairy manure filtrate. Energy Agric. 1985;4(3):217-26.

[30] EPA. Final Methane to Markets International Guidance for Quantifying and Reporting the Performance of Anaerobic Digestion Systems for Livestock Manures. Washington DC: U.S. Environmental Protection Agency; 2010.

[31] Monod J. The Growth of Bacterial Cultures. Annu Rev Microbiol. 1949;3(1):371-94.

[32] Umetsu K, Takahata H, Kawamoto T. Effect of temperature on mesophilic anaerobic digestion of dairy cow slurry. Research Bulletin of Obihiro University Series I. 1992;17(4):401-8.

[33] Kaparaju PLN, Rintala JA. Effects of temperature on post-methanation of digested dairy cow manure in a farm-scale biogas production system. Environ Technol. 2003;24(10):1315-21.

[34] Belle AJ, Lansing S, Mulbry W, Weil RR. Anaerobic co-digestion of forage radish and dairy manure in complete mix digesters. Biomass Bioenerg. 2015;178:230-7.

[35] Zeeman G, Sutter K, Vens T, Koster M, Wellinger A. Psychorophilic digestion of dairy cattle and pig manure: Start-up procedures of batch, fed-batch and CSTR-type digesters. Biol Wastes. 1988;26(1):15-31. 
[36] Angelidaki I, Ahring BK. Thermophilic anaerobic digestion of livestock waste: the effect of ammonia. Appl Microbiol Biotechnol. 1993;38(4):560-4.

[37] Karkkainen I, Franti P. Minimization of the Value of Davies-Bouldin Index. In: Hamza M, editor. International Conference of Signal Processing and Communication; Sep 19-22 2000; Malaga, Spain. Anaheim, CA; Calgary (AB): IASTED; 2000. p. 426-32.

[38] Pandey PK, Ndegwa PM, Soupir ML, Alldredge JR, Pitts MJ. Efficacies of inocula on the startup of anaerobic reactors treating dairy manure under stirred and unstirred conditions. Biomass Bioenerg. 2011;35(7):2705-20.

[39] Moller HB, Sommer SG, Ahring B. Methane productivity of manure, straw and solid fractions of manure. Biomass Bioenerg. 2004;26(5):485-95.

[40] Pabon-Pereira CP, De Vries JW, Slingerland MA, Zeeman G, van Lier JB. Impact of crop-manure ratios on energy production and fertilizing characteristics of liquid and solid digestate during codigestion. Environ Technol. 2014;35(19):2427-34.

[41] Demirer GN, Chen S. Effect of retention time and organic loading rate on anaerobic acidification and biogasification of dairy manure. J Chem Technol Biotechnol. 2004;79(12):1381-7.

[42] Rico C, Garcia H, Rico JL. Physical-anaerobic-chemical process for treatment of dairy cattle manure". Bioresour Technol. 2011;102(3):2143-50.

[43] Safley LM, Westerman PW. Performance of a low-temperature lagoon digester. Bioresour Technol. 1992;41(2):167-75.

[44] Park JBK, Craggs RJ. Biogas production from anaerobic waste stabilisation ponds 
treating dairy and piggery wastewater in New Zealand. Water Sci Technol. 2007;55(11):257-64.

[45] Craggs R, Park J, Heubeck S. Methane emissions from anaerobic ponds on a piggery and a dairy farm in New Zealand. Aust J Exp Agric. 2008;48(1-2):142-6.

[46] Sterling MC, Lacey RE, Engler CR, Ricke SC. Effects of ammonia nitrogen on H2 and $\mathrm{CH} 4$ production during anaerobic digestion of dairy cattle manure. Bioresour Technol. 2001;77(1):9-18.

[47] Owen WF, Stuckey DC, Healy JB, Young LY, McCarty PL. Bioassay for monitoring biochemical methane potential and anaerobic toxicity. Water Res. 1979;13(6):485-92.

[48] Li J, Zicari SM, Cui Z, Zhang R. Processing anaerobic sludge for extended storage as anaerobic digester inoculum. Bioresour Technol. 2014 aug;166:201-10.

[49] Martí-Herrero J, Flores T, Alvarez R, Perez D. How to report biogas production when monitoring small-scale digesters in field. Biomass and Bioenergy. 2016;84:31-6.

[50] Morris GR. Anaerobic fermentation of animal wastes: A kinetic and empirical design evaluation [Thesis]. New York: Cornell University; 1976.

[51] Safley LM, Casada ME, Woodbury JW, Roos KF. Global Methane Emissions From Livestock and Poultry Manure. Washington: U.S. Environmental Protection Agency, Air and Radiation; 1992.

[52] Cumming G. Understanding The New Statistics Effect Sizes, Confidence Intervals, and Meta-Analysis. 1st ed. New York: Routledge Taylor \& Francis Group; 2012. 
Table Legends

1 Number of cases (fraction of $\operatorname{cases}^{\mathrm{a}}$ ) reporting secondary quantitative variables according to digester type. . . . . . . . . . . . . . . . . 34

2 Calculations for two meta-analysis models [52] . . . . . . . . . . . . . . 35

3 Wilcoxon's P-values between default $B_{0}$ values from IPCC and $B_{0}$ from database of this work, according to region of the world. . . . . . . 36 


\section{Figure Captions}

$1 \quad$ Keywords and logical connectors used for search of articles for the database. 37

2 Pie-charts for articles in the database classified according to: a) filtering criteria and; b) continent. . . . . . . . . . . . . . . 38

3 Articles in the database according to year of publication. . . . . . . . . 39

4 K-means clusters for first and second principal components of $Y_{\mathrm{CH} 4}$ and:

a) operational variables for batch; b) composition variables for batch;

c) operational variables for continuous and; d) operational variables for semi-continuous digesters. Colours represent different clusters. . . . . . 40

$5 \quad Y_{\mathrm{CH} 4}$ from different digester types found in the literature. Green box-plot: all $Y_{C H 4}$; orange box-plot: $Y_{C H 4}$ which are reported together with $s_{i}$ and $N_{i}$; red circles: results from fixed-effect mode andl; yellow circles: results from random-effect model; . . . . . . . . . . . . . . . . . . . . . 41

6 Maximum $Y_{C H 4}\left(B_{0}\right)$ from batch tests according to regions. Green boxplot: all $B_{0}$ in the developed database; orange box-plot: $B_{0}$ in database which are reported together with $s_{i}$ and $N_{i}$; red circles: results from fixed-effect model; yellow circles: results from random-effect model and; blue circles: IPCC default values (IPCC 2006, [15]); . . . . . . . . . . . 42 


\section{Tables and Figures}

Table 1: Number of cases (fraction of cases $^{\mathrm{a}}$ ) reporting secondary quantitative variables according to digester type.

\begin{tabular}{|c|c|c|c|c|}
\hline Secondary Variables & [Units] & Batch & Continuous & Semi-continuous \\
\hline \multicolumn{5}{|l|}{ Operation conditions } \\
\hline Time $^{b}$ & {$[d]$} & $1,260(97.0 \%)$ & $326(97.3 \%)$ & $332(64.7 \%)$ \\
\hline Working volume & {$\left[m^{3}\right]$} & $1,286(99.0 \%)$ & $311(92.8 \%)$ & $513(100 \%)$ \\
\hline Temperature & {$\left[{ }^{\circ} \mathrm{C}\right]$} & $1,288(99.1 \%)$ & $291(86.9 \%)$ & $509(99.2 \%)$ \\
\hline $\begin{array}{r}\text { Organic loading } \\
\text { rate }(\mathrm{OLR})\end{array}$ & {$\left[\mathrm{kg} \cdot \mathrm{m}^{-3} \mathrm{~s}^{-1}\right]$} & n.a. & $277(82.7 \%)$ & $377(73.5 \%)$ \\
\hline \multicolumn{5}{|l|}{ Chemical composition } \\
\hline $\mathrm{pH}$ & n.a. & $785(60.4 \%)$ & $115(34.3 \%)$ & $348(67.8 \%)$ \\
\hline Dry matter $(\mathrm{DM})$ & {$\left[\mathrm{kg} \cdot \mathrm{kg}^{-1}\right]$} & $1,078(83.0 \%)$ & $232(69.2 \%)$ & $470(91.6 \%)$ \\
\hline Volatile solids (VS ) & {$\left[\mathrm{kg} \cdot \mathrm{kg}^{-1}\right]$} & $1,063(81.8 \%)$ & $231(69.0 \%)$ & $505(98.4 \%)$ \\
\hline $\begin{array}{l}\text { Chemical oxygen } \\
\text { demand (COD ) }\end{array}$ & {$\left[\mathrm{kg} \cdot \mathrm{m}^{-3}\right]$} & $653(50.3 \%)$ & $183(54.6 \%)$ & $304(59.3 \%)$ \\
\hline $\begin{array}{l}\text { Total Kjeldahl } \\
\text { nitrogen }(\mathrm{TKN})\end{array}$ & {$\left[\mathrm{kg} \cdot \mathrm{m}^{-3}\right]$} & $726(55.9 \%)$ & $159(77.3 \%)$ & $303(59.1 \%)$ \\
\hline
\end{tabular}

${ }^{a}$ Fraction of cases that report secondary variable with respect to total cases of specific digester (in \%) for that type of digester. ${ }^{b}$ Time for batch and hydraulic retention time (HRT)

for continuous and semi-continuous digesters, respectively. 
Table 2: Calculations for two meta-analysis models [52].

\begin{tabular}{|l|c|c|}
\hline Steps for calculation. & Fixed-Effect & \multicolumn{1}{|c|}{ Random-Effect } \\
\hline 1. Variance of case "i" & \multicolumn{2}{|c|}{$V_{i}=s_{i}^{2} / N_{i}$} \\
\hline 2. Initial weight of case "i" & \multicolumn{2}{|c|}{$W_{i}=1 / V_{i}$} \\
\hline 2. Measure of heterogeneity & n.a. & $Q=\sum W_{i} M_{i}^{2}-\frac{\left(\sum W_{i} M_{i}\right)^{2}}{\sum W_{i}}$ \\
\hline 3. Std. deviation of sample & n.a & $T^{2}=\frac{Q-(k-1)}{W_{i}-\sum W_{i}^{2} / \sum W i}$ \\
\hline 4. Variance of case "i"1 & $V_{i}$ & $V_{i}^{*}=V_{i}+T^{2}$ \\
\hline 5. Weight of case "i"1 & $W_{i}$ & $W_{i}^{*}=1 / V_{i}^{*}$ \\
\hline 6. Mean of sample & $M=\sum W_{i} M_{i} / \sum W_{i}$ & $M^{*}=\sum W_{i}^{*} M_{i} / \sum W_{i}^{*}$ \\
\hline 7. Variance of sample & $V_{M}=1 / \sum W_{i}$ & $V_{M}=1 / \sum W_{i}^{*}$ \\
\hline 8. Std. deviation & $\sqrt{V_{M}}$ & $\sqrt{V_{M^{*}}}$ \\
\hline 9. Confidence interval $(C I)$ & {$\left[M \mp z_{C / 100} \sqrt{V_{M}}\right]$} & {$\left[M^{*} \mp z_{C / 100} \sqrt{V_{M^{*}}}\right]$} \\
\hline
\end{tabular}

${ }^{1}$ For the fixed-effect model, case variances and weights are calculated in Steps 1-2. $k$ : number of cases; $z_{C / 100}$ : critical value for confidence interval of $95 \%$ (assumed 1.96 from [52]). 
Table 3: Wilcoxon's P-values between default $B_{0}$ values from IPCC and $B_{0}$ from database of this work, according to region of the world.

\begin{tabular}{|l|cccc|}
\hline$B_{0}$ group & $\begin{array}{c}\text { Asia, Middle } \\
\text { East \& Indian } \\
\text { Subcontinent }\end{array}$ & $\begin{array}{c}\text { West \& East } \\
\text { Europe }\end{array}$ & $\begin{array}{c}\text { North } \\
\text { America }\end{array}$ & Africa \\
\hline All $B_{0}$ in database & $0.023(38)$ & $1.000(76)$ & $0.908(24)$ & $0.571(5)$ \\
Subgroup $B_{0}{ }^{\text {a }}$ & $0.033(7)$ & $0.916(36)$ & $0.474(8)$ & $0.400(2)$ \\
\hline
\end{tabular}

"Subgroup of "All $B_{0}$ " which report specific $N_{i}$ and $s_{i}$, thus, can be used for meta-analysis models. Numbers of cases of $B_{0}$ in database in parenthesis. 


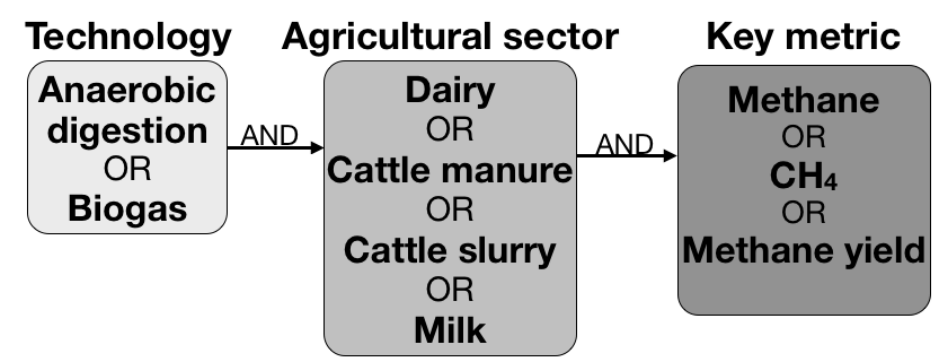

Figure 1: Keywords and logical connectors used for search of articles for the database. 

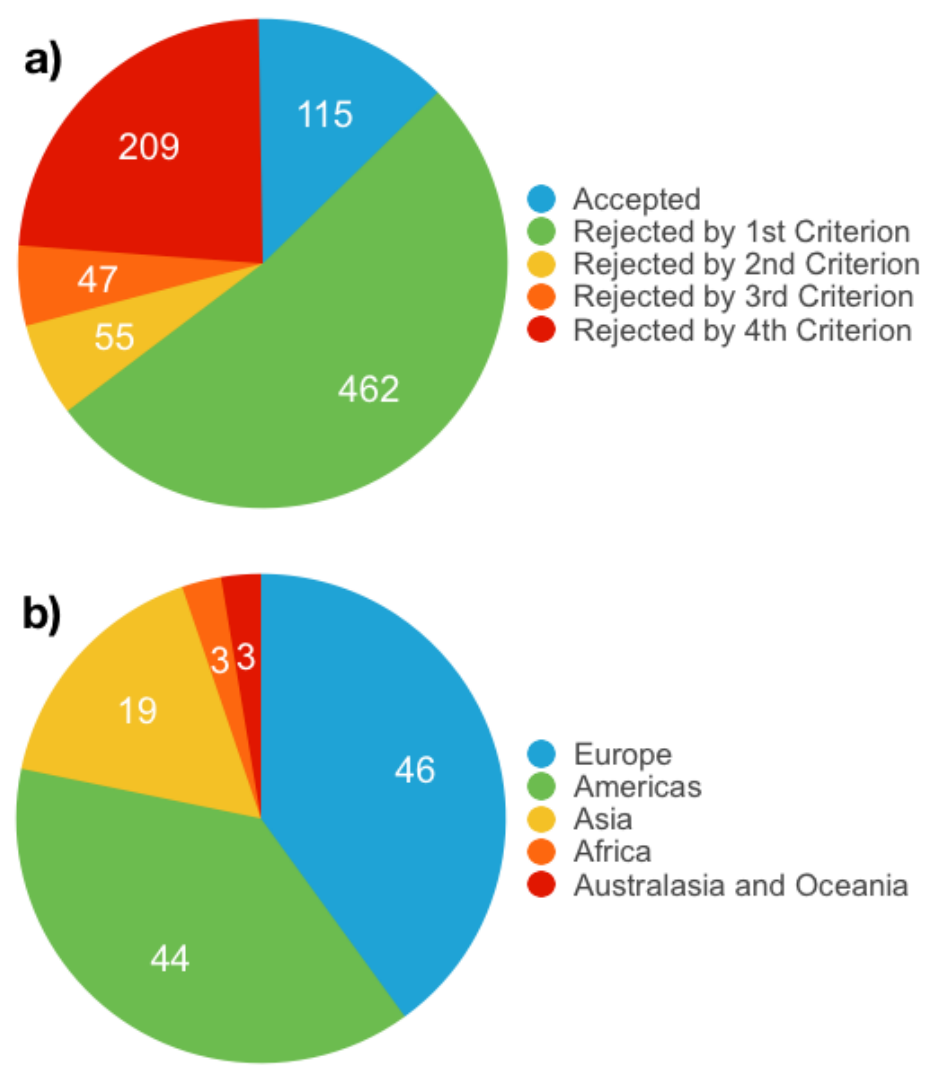

Figure 2: Pie-charts for articles in the database classified according to: a) filtering criteria and; b) continent. 


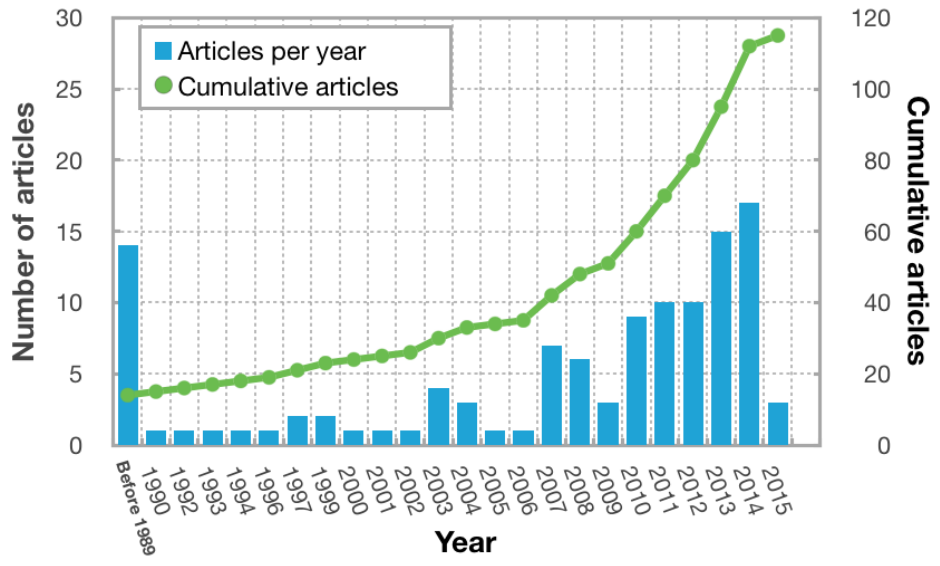

Figure 3: Articles in the database according to year of publication. 


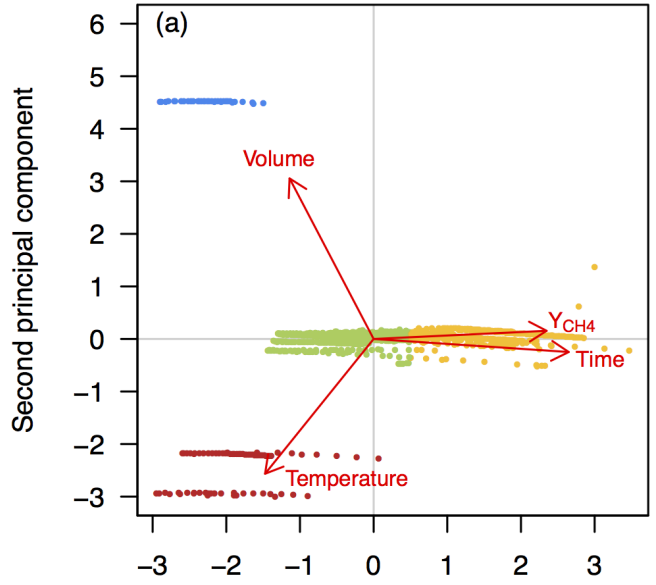

First principal component

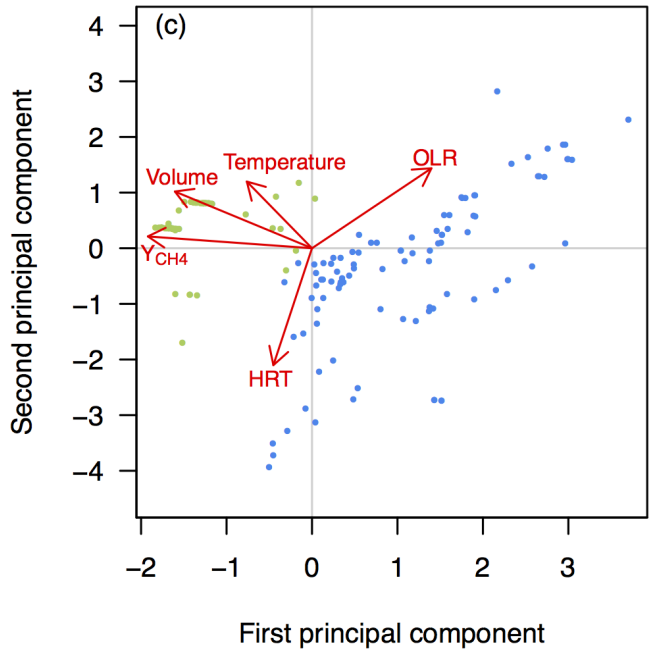

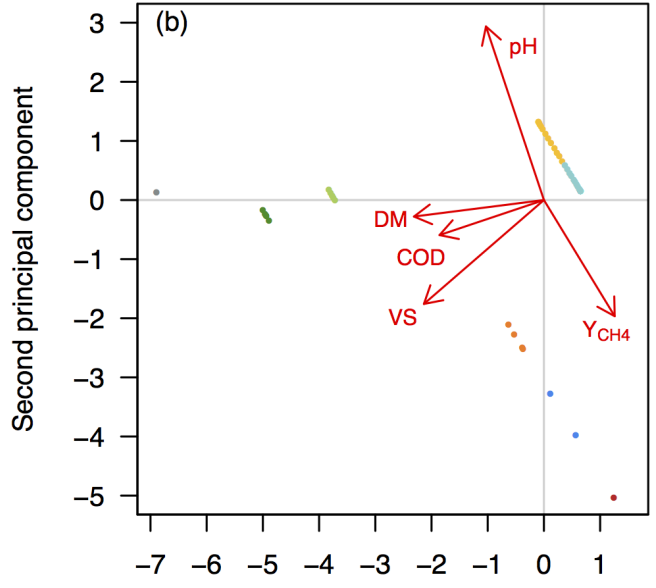

First principal component

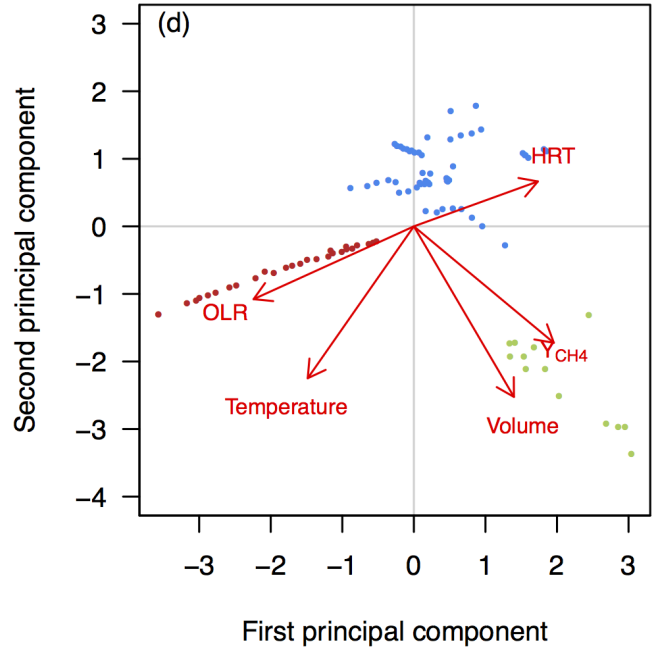

Figure 4: K-means clusters for first and second principal components of $Y_{C H 4}$ and: a) operational variables for batch; b) composition variables for batch; c) operational variables for continuous and; d) operational variables for semi-continuous digesters. Colours represent different clusters. 


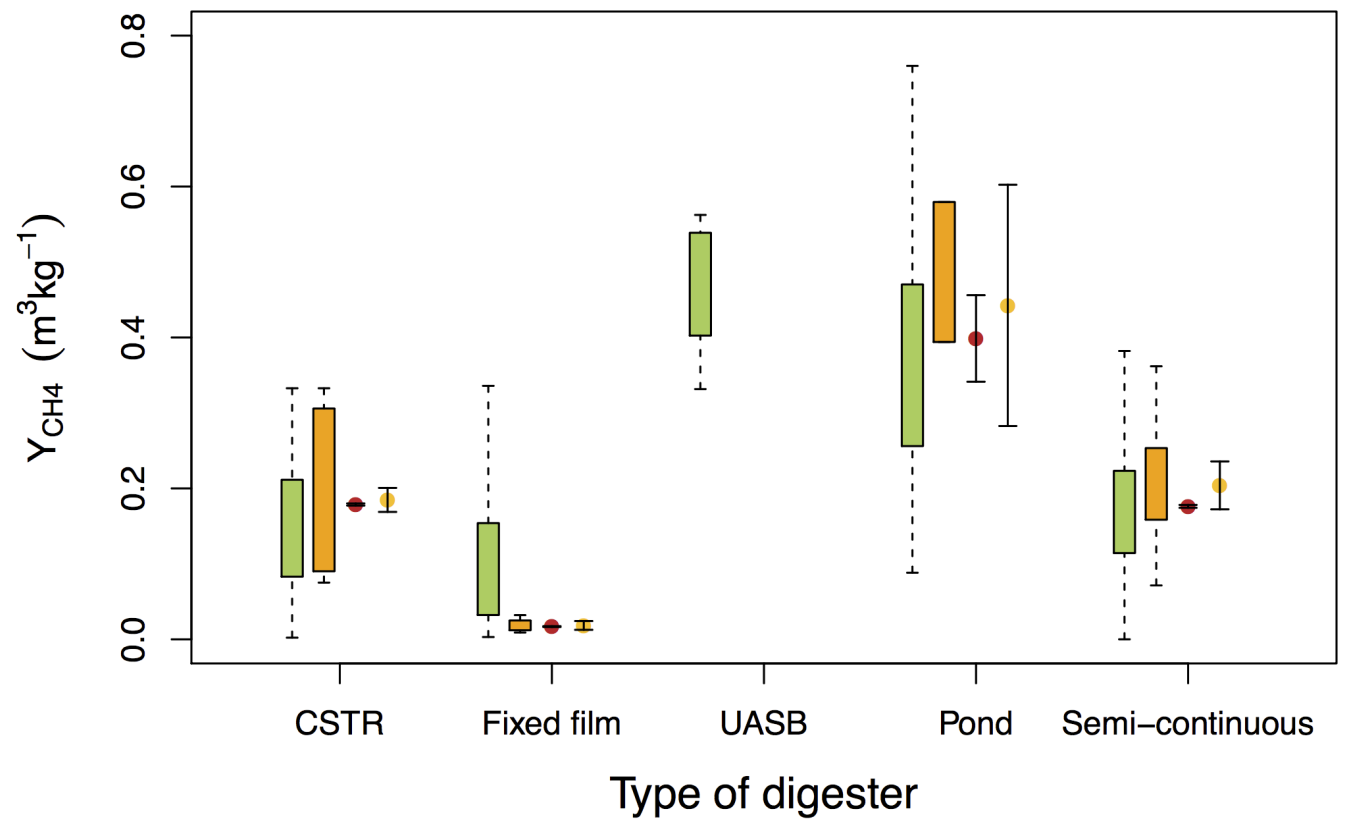

Figure 5: $Y_{\mathrm{CH} 4}$ from different digester types found in the literature. Green box-plot: all $Y_{\mathrm{CH} 4}$; orange box-plot: $Y_{C H 4}$ which are reported together with $s_{i}$ and $N_{i}$; red circles: results from fixed-effect mode andl; yellow circles: results from random-effect model; 


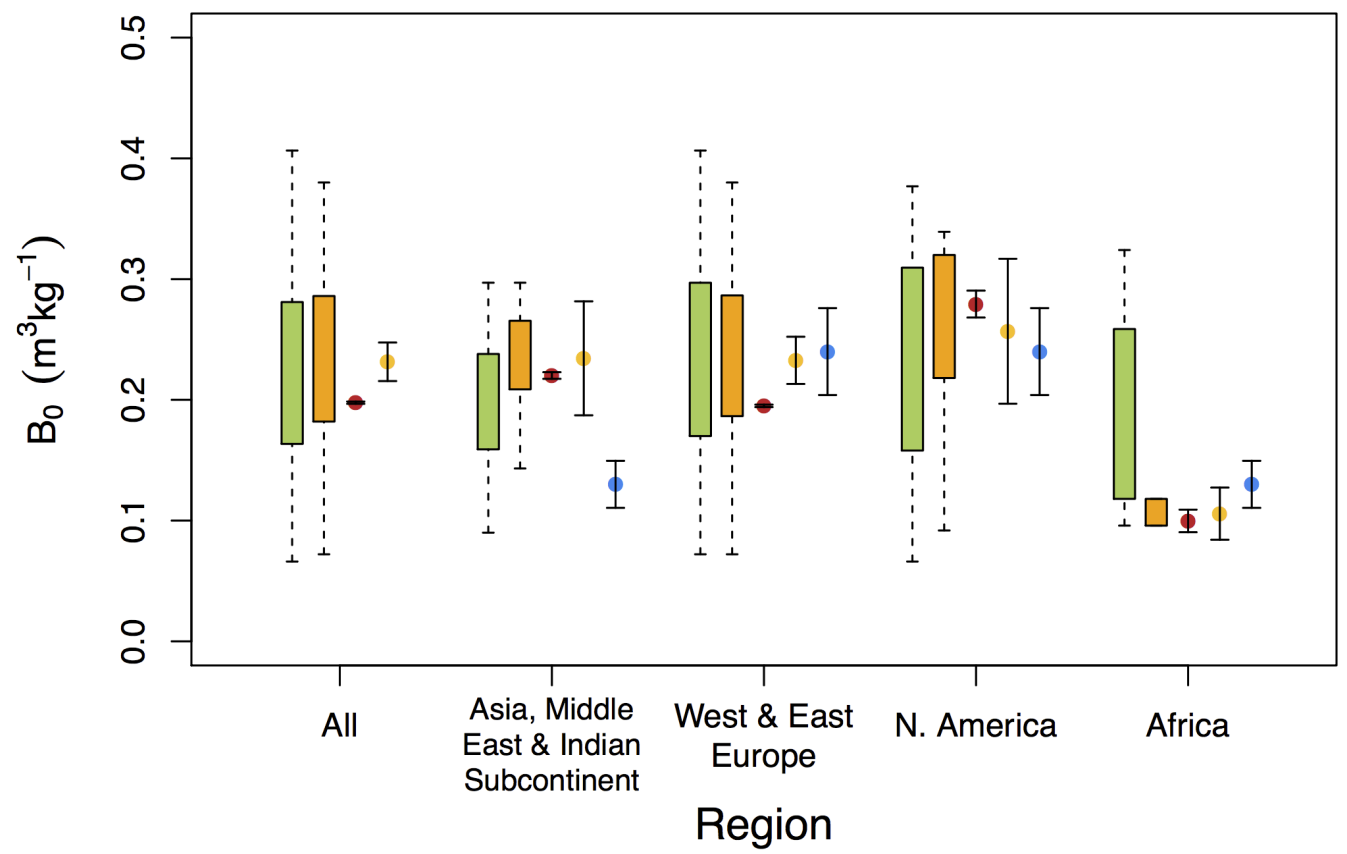

Figure 6: Maximum $Y_{C H 4}\left(B_{0}\right)$ from batch tests according to regions. Green box-plot: all $B_{0}$ in the developed database; orange box-plot: $B_{0}$ in database which are reported together with $s_{i}$ and $N_{i}$; red circles: results from fixed-effect model; yellow circles: results from random-effect model and; blue circles: IPCC default values (IPCC 2006, [15]); 